\section{JTI}

JOURNAL OF

TRAUMA AND INJURY

\title{
Keep Playing Tug-of-War Against Grim Reaper
}

\author{
Kun Hwang, M.D., Ph.D. \\ Department of Plastic Surgery, Inha University School of Medicine, Incheon, Korea
}

Received: December 7, 2020

Accepted: December 8, 2020

\section{Correspondence to}

Kun Hwang, M.D., Ph.D.

Department of Plastic Surgery, Inha University Hospital, 27 Inhang-ro, Jung-gu, Incheon 22332, Korea Tel: +82-32-890-3514 Fax: +82-32-890-2918 E-mail: jokerhg@inha.ac.kr http://www.jtraumainj.org
As you all know well, the aim of the Korean Society of Traumatology (KST) is to reduce the death and disability rates of trauma victims through academic progress in the treatment of trauma patients. The KST held its first annual conference in 1986 and its 27th conference in 2012. Starting in 2013, the KST collaborated with the Armed Forces Medical Command (AFMC) to host the Pan-Pacific Trauma Congress (PPTC) annually; this continued until the seventh congress in 2019. In 2020, an online congress was held because of coronavirus disease-19; however, we will continue to host the PPTC as soon as the pandemic subsides. The KST is participating in major national projects, such as a consultation guideline for trauma patients in Korea and a quality control guideline.

The Korean government implemented a regional trauma center (RTC) project in 2012, with the goal of reducing the preventable trauma death rate (PTDR) to the level of developed countries. RTCs should organically cooperate with the Korean government and the KST to ensure that seriously injured patients are treated at regional level 1 trauma centers [1]. Owing to the efforts of our KST members, the PTDR decreased from $50.4 \%$ in 1990 s to $19.9 \%$ in 2017 [2,3].

I am honored to become the president of the KST this year. This will be my last opportunity to serve the KST, because only 2 years are left before my retirement.

In my role as president, I would like to enhance knowledge-sharing among our members by providing more opportunities for academic communication. I also hope to raise KST's status to a higher level in the global academic community.

Of particular note, our official journal, Journal of Trauma and Injury (JTI), which published its first issue in 1988, was included in the Korean Citation Index (KCI) last year (2020). However, its impact factor is still not satisfactory (0.29). We have a long way to go to be registered in PubMed Central (PMC), Scopus, and SCIE. However, this goal is not so far off that it cannot be reached eventually. As the president of the KST and chairman of the ethics committee, I will help the editor of JTI (Gil-Jae Lee) work towards having JTI registered in more databases. (http://creativecommons.org/licenses/by-nc/4.0/) which permits unrestricted noncommercial use, distribution, and reproduction in any medium, provided the original work is properly cited. 


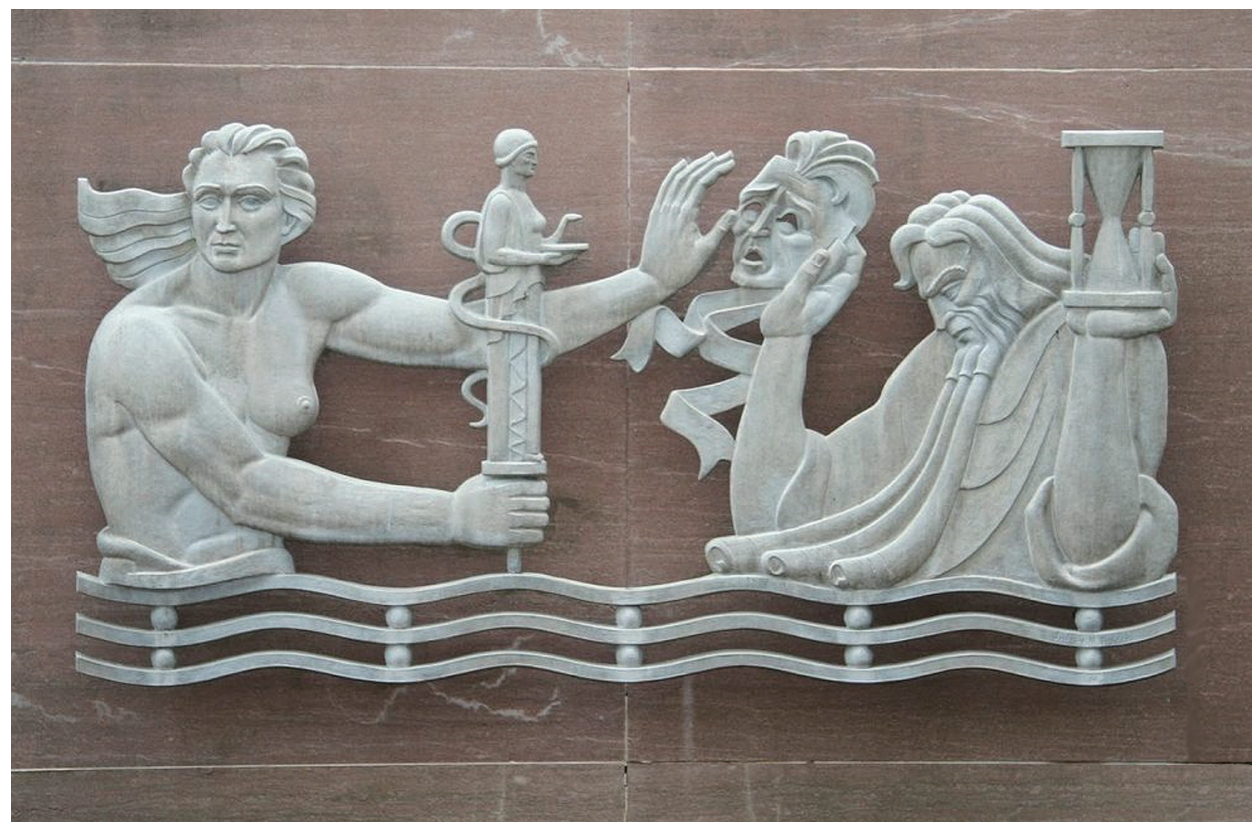

Fig. 1. Holding back the grim reaper. A sculpture on the side of the Fulton County Public Health Department in Atlanta, Georgia. Available from: https://playingintheworldgame.com/2015/09/10/holding-back-the-grim-reaper/.

I eagerly anticipate that our members will submit their valuable manuscripts to JTI, and would be grateful for citations of papers published in JTI. To echo the words of President John F. Kennedy, please do not ask what KST can do for you, but ask what we can do for our KST together.

A well-known movie entitled "Along with the Gods" (2017, starring Ha Jeong-Woo and Cha Tae-Hyun) comes to mind. This film tells the story of a firefighter (Kim Jahong) who dies while saving a girl in a fire in a skyscraper. He is led by three grim reapers who guide him through the seven trials in the afterlife. While watching the movie, I thought about the role of trauma doctors. As trauma doctors, we play tug-of-war against the grim reaper (Fig. 1). If we win, the trauma victim lives. If we lose, the patient dies. If we can decrease the PTDR, our winning rate increases - and to do so, we must share knowledge through academic communication. This is one of the roles of the KST.

The goal of a reaching higher level in the global academic community might not be reached while I am the president of the KST or before my retirement. However, I do believe that if we trauma doctors start building a stone bridge, one by one, to cross the stream, and if our junior trauma doctors continue the task, it will be completed someday in the future.

Here's to trauma doctors! Keep playing tug-of-war against the grim reaper!

\section{ACKNOWLEDGEMENTS}

This study was supported by a grant from National Research Foundation of Korea (NRF-2020R1I1A2054761).

\section{REFERENCES}

1. Park DJ, Park CY, Cho HM, Lee KH, Han HS. Current status and future prospects of trauma centers in Korea. J Korean Med Assoc 2017;60:530-2.

2. Kim H, Jung KY, Kim SP, Kim SH, Noh H, Jang HY, et al. Changes in preventable death rates and traumatic care systems in Korea. J Korean Soc Emerg Med 2012;23:189-97.

3. Jung K, Kim I, Park SK, Cho H, Park CY, Yun JH, et al. Preventable trauma death rate after establishing a national trauma system in Korea. J Korean Med Sci 2019;34:e65. 